NASA/TM-2002-210736

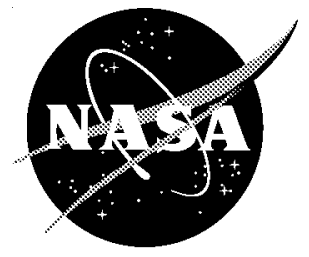

\title{
Initial Flight Tests of the NASA F-15B Propulsion Flight Test Fixture
}

Nathan Palumbo, Timothy R. Moes, and M. Jake Vachon NASA Dryden Flight Research Center

Edwards, California

July 2002 


\section{The NASA STI Program Office...in Profile}

Since its founding, NASA has been dedicated to the advancement of aeronautics and space science. The NASA Scientific and Technical Information (STI) Program Office plays a key part in helping NASA maintain this important role.

The NASA STI Program Office is operated by Langley Research Center, the lead center for NASA's scientific and technical information. The NASA STI Program Office provides access to the NASA STI Database, the largest collection of aeronautical and space science STI in the world. The Program Office is also NASA's institutional mechanism for disseminating the results of its research and development activities. These results are published by NASA in the NASA STI Report Series, which includes the following report types:

- TECHNICAL PUBLICATION. Reports of completed research or a major significant phase of research that present the results of NASA programs and include extensive data or theoretical analysis. Includes compilations of significant scientific and technical data and information deemed to be of continuing reference value. NASA's counterpart of peer-reviewed formal professional papers but has less stringent limitations on manuscript length and extent of graphic presentations.

- TECHNICAL MEMORANDUM. Scientific and technical findings that are preliminary or of specialized interest, e.g., quick release reports, working papers, and bibliographies that contain minimal annotation. Does not contain extensive analysis.

- CONTRACTOR REPORT. Scientific and technical findings by NASA-sponsored contractors and grantees.
- CONFERENCE PUBLICATION. Collected papers from scientific and technical conferences, symposia, seminars, or other meetings sponsored or cosponsored by NASA.

- SPECIAL PUBLICATION. Scientific, technical, or historical information from NASA programs, projects, and mission, often concerned with subjects having substantial public interest.

- TECHNICAL TRANSLATION. Englishlanguage translations of foreign scientific and technical material pertinent to NASA's mission.

Specialized services that complement the STI Program Office's diverse offerings include creating custom thesauri, building customized databases, organizing and publishing research results...even providing videos.

For more information about the NASA STI Program Office, see the following:

- Access the NASA STI Program Home Page at http://www.sti.nasa.gov

- E-mail your question via the Internet to help@sti.nasa.gov

- Fax your question to the NASA Access Help Desk at (301) 621-0134

- Telephone the NASA Access Help Desk at (301) 621-0390

- Write to:

NASA Access Help Desk

NASA Center for AeroSpace Information 7121 Standard Drive Hanover, MD 21076-1320 
NASA/TM-2002-210736

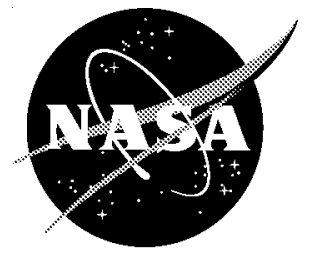

\section{Initial Flight Tests of the NASA F-15B Propulsion Flight Test Fixture}

Nathan Palumbo, Timothy R. Moes, and M. Jake Vachon NASA Dryden Flight Research Center

Edwards, California

National Aeronautics and

Space Administration

Dryden Flight Research Center

Edwards, California 93523-0273

July 2002 


\section{NOTICE}

Use of trade names or names of manufacturers in this document does not constitute an official endorsement of such products or manufacturers, either expressed or implied, by the National Aeronautics and Space Administration.

Available from the following:

NASA Center for AeroSpace Information (CASI)

7121 Standard Drive

Hanover, MD 21076-1320

(301) 621-0390
National Technical Information Service (NTIS) 5285 Port Royal Road Springfield, VA 22161-2171

(703) $487-4650$ 


\title{
INITIAL FLIGHT TESTS OF THE NASA F-15B PROPULSION FLIGHT TEST FIXTURE
}

\author{
Nathan Palumbo, ${ }^{*}$ Tim Moes, ${ }^{\dagger}$ and M. Jake Vachon ${ }^{\ddagger}$ \\ NASA Dryden Flight Research Center, Edwards, California, 93523-0273
}

\begin{abstract}
$\underline{\text { Abstract }}$
Flights of the F-15B/Propulsion Flight Test Fixture (PFTF) with a Cone Drag Experiment (CDE) attached have been accomplished at NASA Dryden Flight Research Center. Mounted underneath the fuselage of an F-15B airplane, the PFTF provides volume for experiment systems and attachment points for propulsion experiments. A unique feature of the PFTF is the incorporation of a six-degree-of-freedom force balance. The force balance mounts between the PFTF and experiment and measures three forces and moments. The CDE has been attached to the force balance for envelope expansion flights. This experiment spatially and inertially simulates a large propulsion test article. This report briefly describes the F-15B airplane, the PFTF, and the force balance. A detailed description of the $\mathrm{CDE}$ is provided. Force-balance ground testing and stiffness modifications are described. Flight profiles and selected flight data from the envelope expansion flights are provided and discussed, including force-balance data, the internal PFTF thermal and vibration environment, a handling qualities assessment, and performance capabilities of the F-15B airplane with the PFTF installed.
\end{abstract}

\section{Nomenclature}

$C_{A} \quad$ coefficient of axial force

CAS control augmentation system

CDE Cone Drag Experiment

KCAS knots calibrated airspeed

NASA National Aeronautics and Space Administration

\footnotetext{
* Aerospace Engineer

$\uparrow$ Aerospace Engineer, Member

$\Varangle$ Aerospace Engineer, Member
}

Note that use of trade names or names of manufacturers in this document does not constitute an official endorsement of such products or manufacturers, either expressed or implied, by the National Aeronautics and Space Administration.

$\begin{array}{ll}\text { PCM } & \text { pulse code modulation } \\ \text { PFTF } & \text { Propulsion Flight Test Fixture } \\ \bar{q} & \text { dynamic pressure, } \mathrm{lbf} / \mathrm{ft}^{2} \\ \text { RBCC } & \text { rocket-based combined cycle } \\ \zeta & \text { damping } \\ \omega_{n} & \text { undamped natural frequency } \\ & \underline{\text { Introduction }}\end{array}$

Initial flight tests have been completed on the NASA F-15B/Propulsion Flight Test Fixture (PFTF), a new and unique low-cost facility for the development and flight test of advanced propulsion systems and components. The PFTF has undergone a series of envelope expansion flight tests while fitted to the centerline pylon of an F-15B test bed aircraft (fig. 1) at NASA Dryden Flight Research Center (Edwards, California). The purpose of the PFTF is to provide actual flight data in the subsonic, transonic, and supersonic flight regimes at an early stage in the development of innovative propulsion concepts.

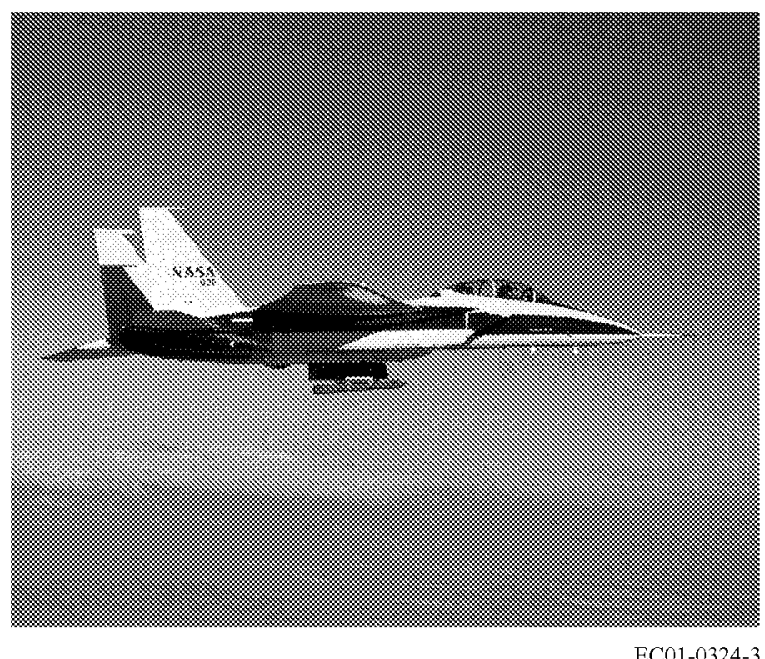

Figure 1. The F-15B/PFTF in flight. 
Traditionally, flight test has been reserved for the last phase of engine development. ${ }^{1}$ Because of the "captive-carry" capability of the PFTF, however, new air-breathing propulsion schemes such as rocket-based combined cycle (RBCC) can be economically brought into flight test using subscale experiments. Mission risk is reduced because the propulsion experiment is not the primary propulsion system of the vehicle. Also, hardware can be reused for multiple flights, unlike a single-use-missile-boosted free-flight test. The PFTF enables relatively low-cost flight testing of new propulsion technologies or components to conditions within the flight envelope of the F-15B aircraft.

The PFTF primarily has been developed at NASA Dryden, relying on previous flight test experience with centerline-mounted test articles on the F-15B airplane. ${ }^{2}$ The PFTF provides space for propellants and feed systems and is equipped with a force balance. The force balance mounts between the PFTF and the experiment and measures three moments and three forces (fig. 2).

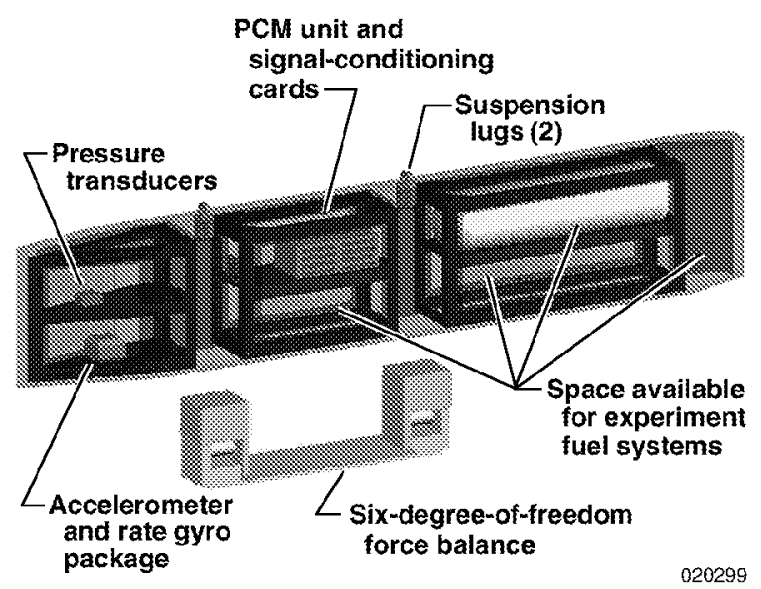

Figure 2. The PFTF and force balance.

For the initial envelope expansion flights, a test article known as the Cone Drag Experiment (CDE) was installed on the PFTF. The CDE spatially and inertially approximates a typical propulsion experiment that could be carried by the PFTF, and the aerodynamic and inertial forces generated by the CDE in flight were measured by the PFTF force balance. Reference 3 provides a detailed description of the design and development of the PFTF, force balance, and CDE.
Envelope expansion flights have been conducted to clear the F-15B/PFTF configuration for flutter and handling qualities concerns and to demonstrate the Mach performance capability of the configuration. Other significant objectives of the flight test program have been to flight-qualify the force balance and to characterize the internal PFTF thermal and vibration environment. Selected flight results are presented herein to demonstrate performance and handling qualities of the F-15B/PFTF configuration, force-balance measurement repeatability and noise, and internal PFTF environmental conditions.

\section{Flight Test Configuration}

The flight test configuration consists of the PFTF attached to the centerline pylon of an F-15B airplane. An adapter is used to connect the CDE to the PFTF force balance. To verify the design and operation of the PFTF, its components, and its predicted effect on aircraft performance and handling, envelope expansion flights have been performed with the CDE installed.

\section{The F-15B Test Bed Airplane}

The F-15B aircraft is a two-seat fighter/trainer version of the high-performance, supersonic, air-superiority F-15 fighter aircraft built by the McDonnell Aircraft Company (now The Boeing Company, St. Louis, Missouri). The aircraft is powered by two F100-PW-100 turbofan engines with afterburners manufactured by Pratt \& Whitney Aircraft Engines (West Palm Beach, Florida). Each engine has an uninstalled, sea-level static thrust rating of approximately $25,000 \mathrm{lbf}$. The F-15B aircraft has a length of $63.7 \mathrm{ft}$ and a wingspan of $42.8 \mathrm{ft}$. The basic operating weight of the aircraft is $27,500 \mathrm{lb}$, with a maximum takeoff gross weight of $54,000 \mathrm{lb}^{2}$

A NASA Dryden-operated F-15B airplane has been converted to a research test bed airplane. Research instrumentation, recording, telemetry, and video systems have been installed on the airplane. The airplane also is equipped with a noseboom to measure angle of attack, angle of sideslip, total pressure, and static pressure and has an instrumentation pallet in the aircraft ammunition bay that contains data recording and telemetering equipment.

\section{The Propulsion Flight Test Fixture and Cone Drag Experiment}

The PFTF was attached to the centerline pylon of the F-15B airplane using procedures similar to those used in attaching a centerline tank. The PFTF main structure is manufactured from a single piece of 6061 aluminum 
and has internal room for three racks of equipment and the force balance (fig. 2). The force balance is primarily constructed of 2024 aluminum, except for the load-measuring tubes, which are constructed of 17-4 stainless steel. These tubes each have five strain-gage bridges whose outputs are converted to three moments and three forces that are monitored in real time in the control room. The CDE weighs $340 \mathrm{lb}$; figure 3 shows its dimensions. The CDE has two main components: the adapter and the coned tube.
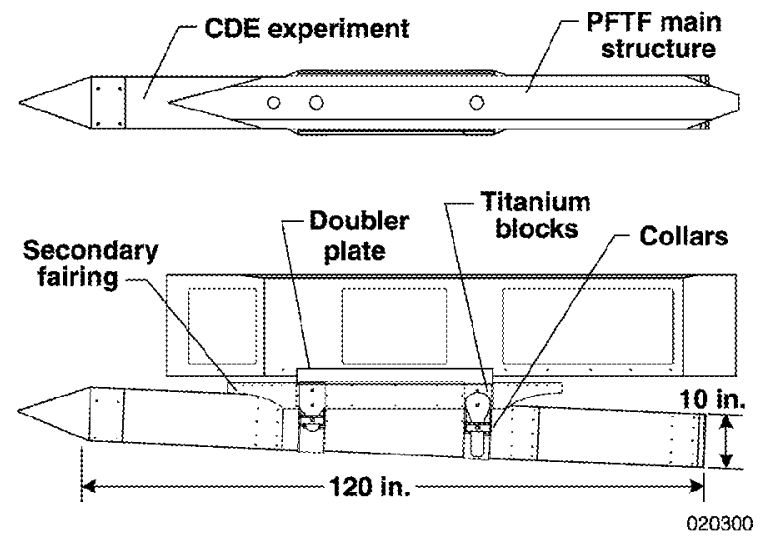

Figure 3. PFTF-CDE configuration.

The main purpose of the CDE adapter is to provide a structural mount for the coned tube to the force balance. All main structure has been designed to a minimum factor of safety of 2.25 . Because of large weight margins and a focus on robustness, however, most factors were in excess of 4 . The primary structure consists of titanium blocks and stainless steel bars and collars. The blocks mount to the underside of the PFTF force balance, and the bars mate to the blocks and collars with 3/8-in. stainless steel bolts. The coned tube is retained in the axial direction by the collars with two cylindrical stainless steel keys.

The design of the adapter allows for the experiment angle of attack to be changed by using bars of varying length. The angle of attack for all of the CDE flights was $2.5^{\circ}$ noseup. This noseup attitude was used to align the CDE with the local flow, which varies with Mach number. ${ }^{2}$ The aft set of bars is pinned to allow for thermal expansion of the tube.

The secondary structure is constructed of $1 / 8$-in.-thick aluminum and provides for aerodynamic fairing and mounting space for instrumentation. Pressure transducers are located between the titanium blocks, eliminating the need to run large amounts of pressure tubing across the metric break of the force balance.

The coned tube is constructed of three pieces of 1/2-in.-thick 6061 aluminum tubing that has an outside diameter of $10 \mathrm{in}$. The cone and base plate assembly of the tube are constructed of 2024 aluminum and mounted with a similar lap joint.

The CDE configuration remained unchanged for the first four flights. For the last flight, the 20-deg half-angle nosecone was replaced with a $30-$ deg one.

\section{Force-Balance Stiffness and Configuration}

The PFTF force balance uses two load-measuring tubes to determine forces and moments (fig. 4). For the balance to function properly, the only significant deflections must be in the load-measuring tubes. The "ground" sides of these two tubes are mechanically joined by a 1/2-in. aluminum plate and the main structure of the PFTF, which allows for very little relative motion between the two ground ends. The "live" sides of the load tubes are mechanically joined by a 1/2-in.-thick aluminum plate.

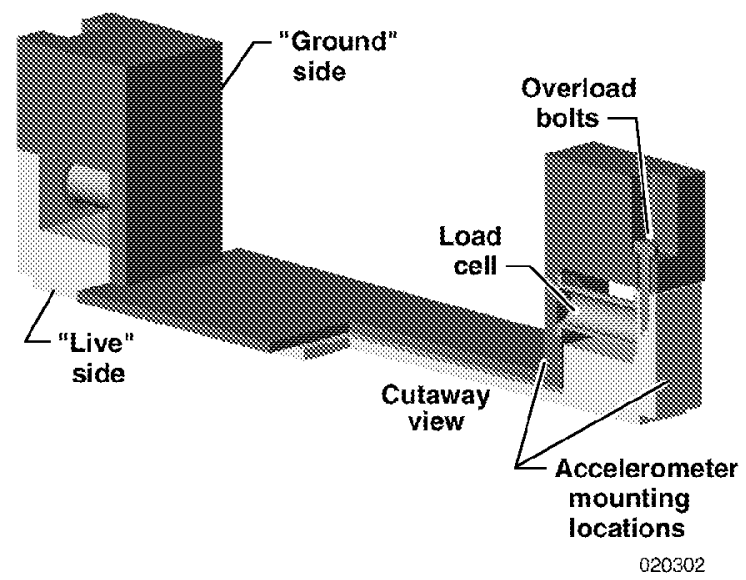

Figure 4. Force balance detail.

During initial ground tests at NASA Dryden with the CDE installed, the force balance showed more than 30 -percent error in the axial direction. This inaccuracy was determined to be caused by pitching moments from the axial force causing the "live" blocks to rotate in relation to each other. This lack of stiffness and resulting relative rotation did not affect the original calibration because a large, steel, calibration test article bridged 
both live blocks, adding stiffness to the live side of the balance.

The CDE did not have the inherent pitching stiffness of this calibration test article. To fix this problem with minimal impact on the experiment, a doubler plate was built to fit between the force balance and CDE. Aluminum was chosen rather than steel to match the thermal expansion properties of the force balance. The table shows a comparison of the stiffness increase from this doubler plate with the calibration and the original configuration. The stiffness has been increased nearly two orders of magnitude with the addition of the doubler plate; however, the stiffness is still more than an order of magnitude less than it was during the original calibration.

To verify that this level of stiffness is acceptable, the PFTF, force balance, and doubler plate were tested using a setup that applied loads to the force balance in the same way that the CDE applied loads. Figure 5 shows the results of the axial tests. The ground test showed the original calibration to be accurate to 3 percent of the true load in the axial direction for loads to a maximum of $500 \mathrm{lbf}$. Thus, the original calibration was updated and used to analyze all flight data.

When fastening the doubler plate to the force balance during initial installation, significant loads were observed being imparted to the load-measuring tubes. These loads were determined to be caused by manufacturing tolerances in flatness between the force-balance lower surface and the upper surface of the doubler plate. The force balance was being forced to conform to the stiffer doubler plate, thus causing strain in the load-measuring tubes. Feeler gauges were used to identify a maximum 0.005 -in. gap between the surfaces. To alleviate this gap, a coating of liquid steel filler was applied inbetween the two surfaces. The fastening bolts were installed and torqued to 10 percent of the normal value. The filler was allowed to harden, then the fasteners were torqued to the final value. This method significantly reduced the strain in the force balance caused by attaching the doubler plate.

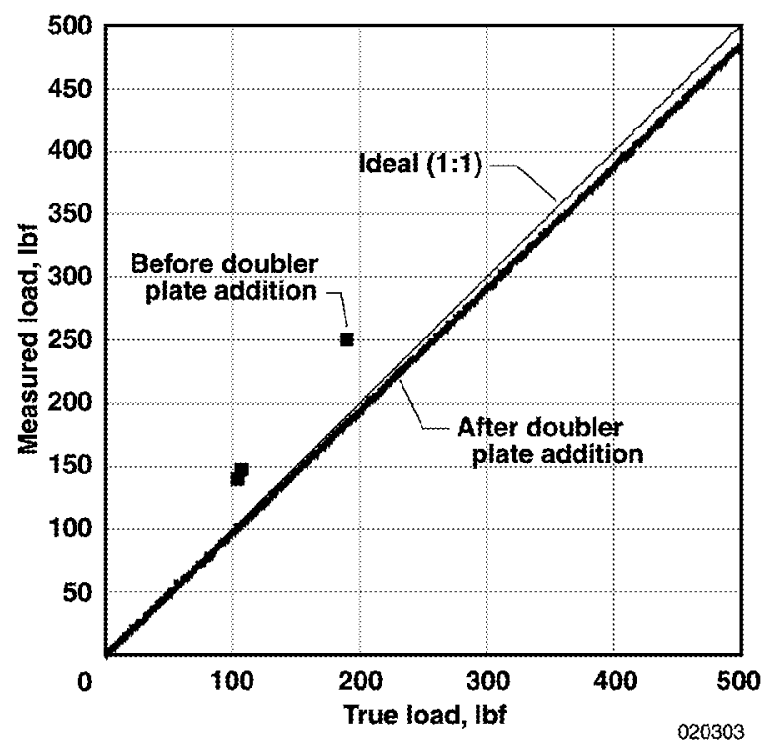

Figure 5. Force-balance ground tests, axial direction.

Instrumentation and Local Flow

The airplane noseboom measures total pressure, static pressure, angle of attack, and angle of sideslip. The F-15B airplane contains a motion pack in the ammunition bay that measures accelerations and rates. The PFTF is equipped to monitor temperatures, pressures, and the force-balance strain gages. Thermocouples are mounted in each bay of the PFTF. A total-temperature probe is located on the aft left side of

Table. Force-balance "live" plate pitching stiffness.

\begin{tabular}{lccc}
\hline \hline Test article & Material & $\begin{array}{c}\text { Moment of } \\
\text { inertia, in }\end{array}$ & $\begin{array}{c}\text { Flexural rigidity (EI), } \\
\left(\text { lbf } \times \text { in }{ }^{2}\right)\end{array}$ \\
\hline $\begin{array}{c}\text { Manufacturer's calibration } \\
\text { test article (estimated) }\end{array}$ & Steel & 77.650 & $2.26 \times 10^{6}$ \\
CDE without stiffener plate & $\begin{array}{c}2024-\mathrm{T} 3 \\
\text { aluminum }\end{array}$ & 0.060 & 642 \\
CDE with stiffener plate & $\begin{array}{c}2024-\mathrm{T} 3 \\
\text { aluminum }\end{array}$ & 4.250 & 45,475 \\
\hline \hline
\end{tabular}


the PFTF. Base pressures of the CDE are also instrumented (fig. 6). Accelerometers mounted at each end of the CDE measure accelerations in the lateral and vertical direction. Accelerometers are also mounted internal to the PFTF (fig. 3).

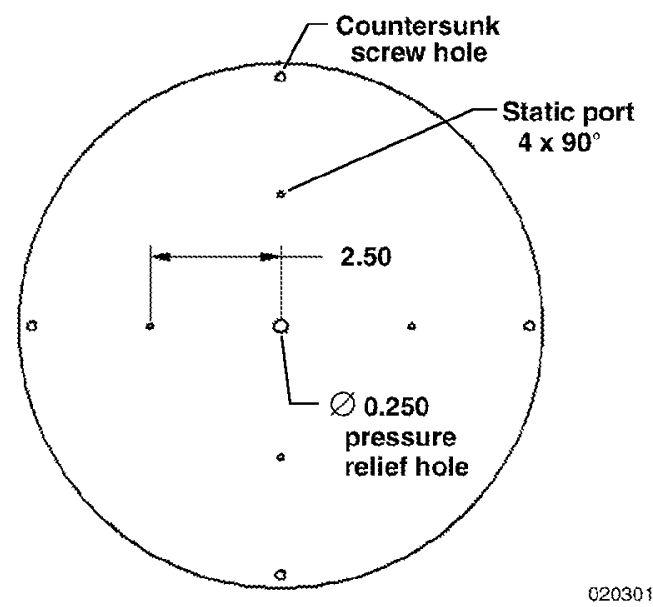

Figure 6. Coned tube base.

Local flow around the PFTF can differ at supersonic speeds because of the bow shock wave produced by the F-15B airplane. Previous flight tests have shown local Mach number below the F-15B airplane to be as much as 15-percent less at speeds as fast as Mach 1.7. Because local Mach number was not measured during PFTF flight tests, what the local Mach number will be for free-stream Mach numbers greater than 1.7 is uncertain. A future experiment is planned to quantify the local Mach number in this region.

\section{Flight Test Approach and Results}

A five-flight envelope expansion program has been conducted with the PFTF and CDE installed. Figure 7 shows the PFTF design envelope and test points flown. Accelerations for flutter clearance have been performed at altitudes of 15,30 , and $40 \mathrm{kft}$. No pilot stick or rudder inputs were required for flutter clearance.

The circle symbols in figure 7 represent handling-quality test points that were sequentially flown from lesser to greater Mach numbers at each altitude. At these test conditions, the pilot initiated a pitch doublet followed by a yaw doublet with the control augmentation system (CAS) active in all axes. The pilot then disengaged the CAS for the yaw and roll axes and conducted another yaw doublet. The pilot let any oscillations damp out before inputting additional stick and rudder pedal commands. If the aircraft response was considered acceptable, the pilot proceeded with the acceleration to the next greater Mach-number test point.

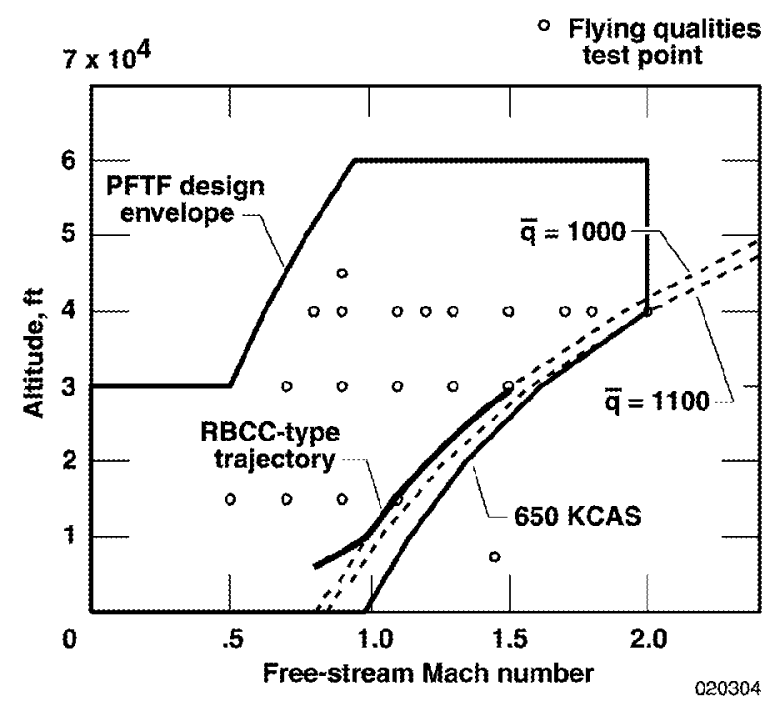

Figure 7. Envelope expansion test points.

Force-balance flight qualification has been accomplished by measuring repeatability of results from various flights, which also demonstrated the robustness of the strain-gage measurement system. The bluntness of the conical forebody of the CDE was also varied to qualitatively assess the accuracy of the force-balance drag measurement.

A maximum-performance climb maneuver was conducted on the last flight to demonstrate a dynamic pressure $(\bar{q})$ profile through the transonic Mach numbers that is typical of advanced propulsion concepts such as RBCC. This maneuver was conducted at the full afterburner power setting starting from a speed of Mach 0.8 at an altitude of $6 \mathrm{kft}$ and accelerating to a dynamic pressure of $1000 \mathrm{lbf} / \mathrm{ft}^{2}$ at a speed of Mach 1.0, then continuing the acceleration at a constant dynamic pressure of $1000 \mathrm{lbf} / \mathrm{ft}^{2}$.

\section{$\underline{\text { Flutter }}$}

Analysis of ground vibration tests of the PFTF show large margins for flutter; however, accelerometers mounted on the CDE were monitored from the control room for each flight to verify safe margins. Level accelerations for flutter clearance were performed at 
altitudes of 15,30 , and $40 \mathrm{kft}$. Real-time analysis of accelerometer flight data revealed no flutter concerns for the PFTF with the CDE.

\section{Handling and Flying Qualities Flight Test Results}

Reference 3 predicts that the F-15B/PFTF-CDE configuration will have slightly reduced directional stability and dihedral effect compared with the "clean" F-15B configuration. This reduced stability and dihedral effect potentially could result in reduced lateral-directional handling qualities. Piloted simulation studies predicted that the "Level 1"4 handling qualities of the F-15B airplane would be unaffected by the addition of the PFTF and CDE for flight at any Mach number with the CAS operating. Simulation studies also predicted that the handling qualities of the dutch-roll mode for the clean F-15B configuration would degrade from Level 1 to Level $2^{4}$ as Mach number increased with the CAS for the yaw and roll axes turned off.

An objective of this flight envelope expansion has been to determine if the PFTF-CDE configuration adversely affects handling qualities with the CAS in the yaw and roll axes turned off. Pilot-input rudder doublets were used to excite the dutch-roll mode. Pilot comments pertaining to flying qualities when the CAS was off were used to assess whether or not proceeding to the next greater Mach number would be safe. Postflight analyses of the angle-of-sideslip time histories were used to analytically estimate the handling qualities level.

Figure 8 shows a quantitative analysis of dutch-roll-mode handling qualities for flight at altitudes of 30 and $40 \mathrm{kft}$ with the CAS off. Undamped natural frequency $\left(\omega_{n}\right)$ and damping $(\zeta)$ were obtained from simulation and flight data and compared with military handling qualities requirements for a fighter aircraft (class IV) in cruise flight (category B). ${ }^{4}$ Level 1 handling qualities are desired. Level 2 implies minor to fairly objectionable deficiencies. Level 3 implies major deficiencies. ${ }^{4}$ The solid lines in figure 8 show $\zeta \omega_{n}$ from simulated data for the clean F-15B configuration. When the CAS is off, Level 2 handling qualities are expected at speeds greater than Mach 0.9 at an altitude of $30 \mathrm{kft}$ and Mach 1.7 at an altitude of $40 \mathrm{kft}$. The square symbols represent simulated data for the F-15B/PFTF-CDE configuration. As can be seen, the small stability and dihedral effect reductions associated with the F-15B/PFTF-CDE configuration did not significantly affect $\zeta \omega_{n}$.

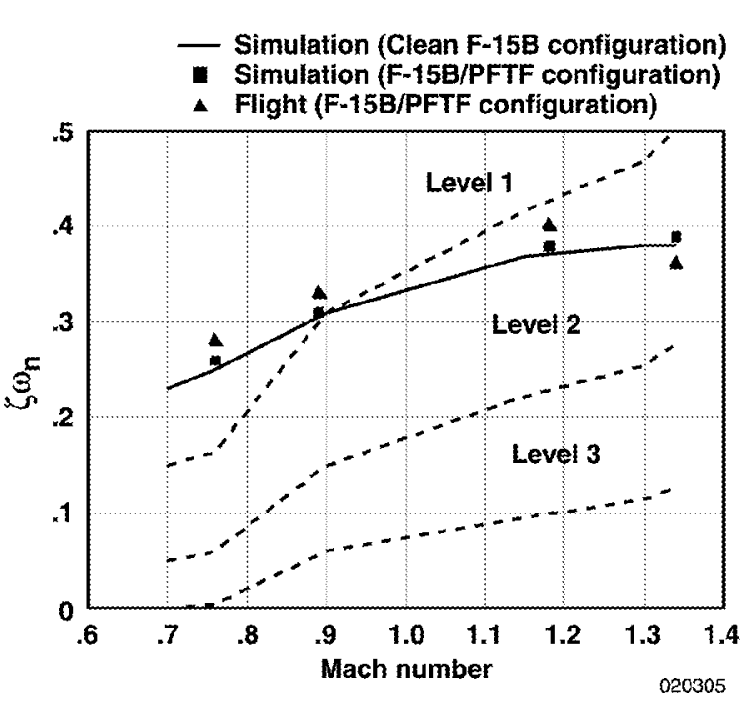

(a) At an altitude of $30 \mathrm{kft}$.

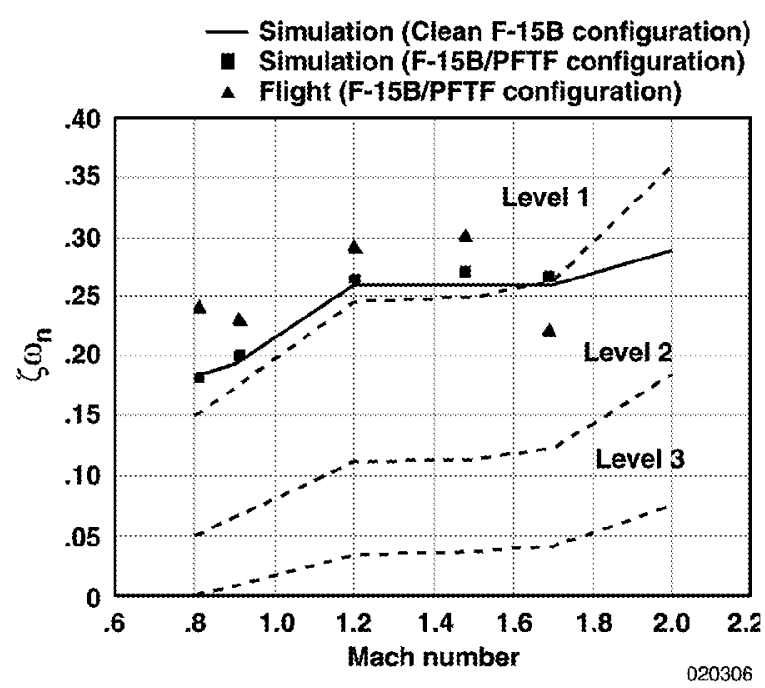

(b) At an altitude of $40 \mathrm{kft}$.

Figure 8. Dutch-roll-mode handling quality analysis with the CAS for the yaw and roll axes turned off.

Flight data from the rudder doublets were used to plot the triangle symbols in figure 8. After the rudder doublet, the pilots allowed the dutch-roll mode to damp out without further control inputs. Curve fits of the noseboom angle-of-sideslip measurement were used to obtain $\zeta \omega_{n}$. At an altitude of $30 \mathrm{kft}$ (fig. 8(a)), the flight results generally tracked the simulator results, showing estimated handling qualities of Level 2 at speeds faster 
than Mach 1. The uncertainty of the analysis technique for $\zeta \omega_{n}$ was estimated to be \pm 0.05 . At an altitude of $40 \mathrm{kft}$ (fig. 8(b)), the flight data show estimated handling qualities of Level 1 and greater dutch-roll-mode damping than predicted; with the exception at Mach 1.7, where estimated handling qualities of Level 2 were obtained.

Pilot comments agree fairly well with the analytical handling qualities assessment shown in figure 8 . The pilots did notice the reduced damping as Mach number increased, but were never concerned that increasing Mach number further would result in unacceptable handling qualities in the event of a CAS failure. Consequently, the envelope expansion proceeded to Mach 2 with no significant handling qualities concerns for the PFTF or CDE.

\section{$\underline{\text { Performance }}$}

The maximum Mach number achieved was 2.0 during the fourth flight at an altitude of $40,080 \mathrm{ft}$ and in a slight dive. A maximum dynamic pressure of $1120 \mathrm{lbf} / \mathrm{ft}^{2}$ was attained at the same time. Maximum performance can vary depending on air temperature, which affects engine performance. On the day of the maximum performance flight, greater Mach numbers could have been achieved because the airplane was still accelerating; however, a preflight-briefed operating limit of Mach 2.0 was observed. The CDE also produces more drag than a typical propulsion experiment with an inlet. Thus, PFTF flight to speeds faster than Mach 2.0 is possible, depending on the experiment geometry.

For the last flight of the PFTF, an access-to-space trajectory for a generic air-breathing vehicle (fig. 9) was attempted. The purpose was to gain acceleration data on how rapidly the $\mathrm{F}-15 \mathrm{~B} / \mathrm{PFTF}$ combination could pass through the transonic region. This acceleration information then could be used to plan an engine test that starts in the subsonic region and continues to supersonic in a single firing while following the space-access trajectory. The planned profile was to be entered at a speed of Mach 0.7 and continued to Mach 1.5 at full afterburner along the profile shown in figure 9. This profile is difficult to fly because the cockpit does not have a dynamic pressure gauge. The pilot must follow an altitude and knots calibrated airspeed (KCAS) profile. Figure 9 shows the data from this flight. Dynamic pressure was maintained to within approximately $50 \mathrm{lbf} / \mathrm{ft}^{2}$ of the target for Mach 0.7-1.25. Because of test point sequencing and fuel constraints, the maneuver was terminated at Mach 1.3.

\section{$\underline{\text { Force-Balance In-Flight Axial Force Measurements }}$}

The PFTF force balance was used to measure the three forces and moments generated by the CDE, which include both inertial and aerodynamic forces. This
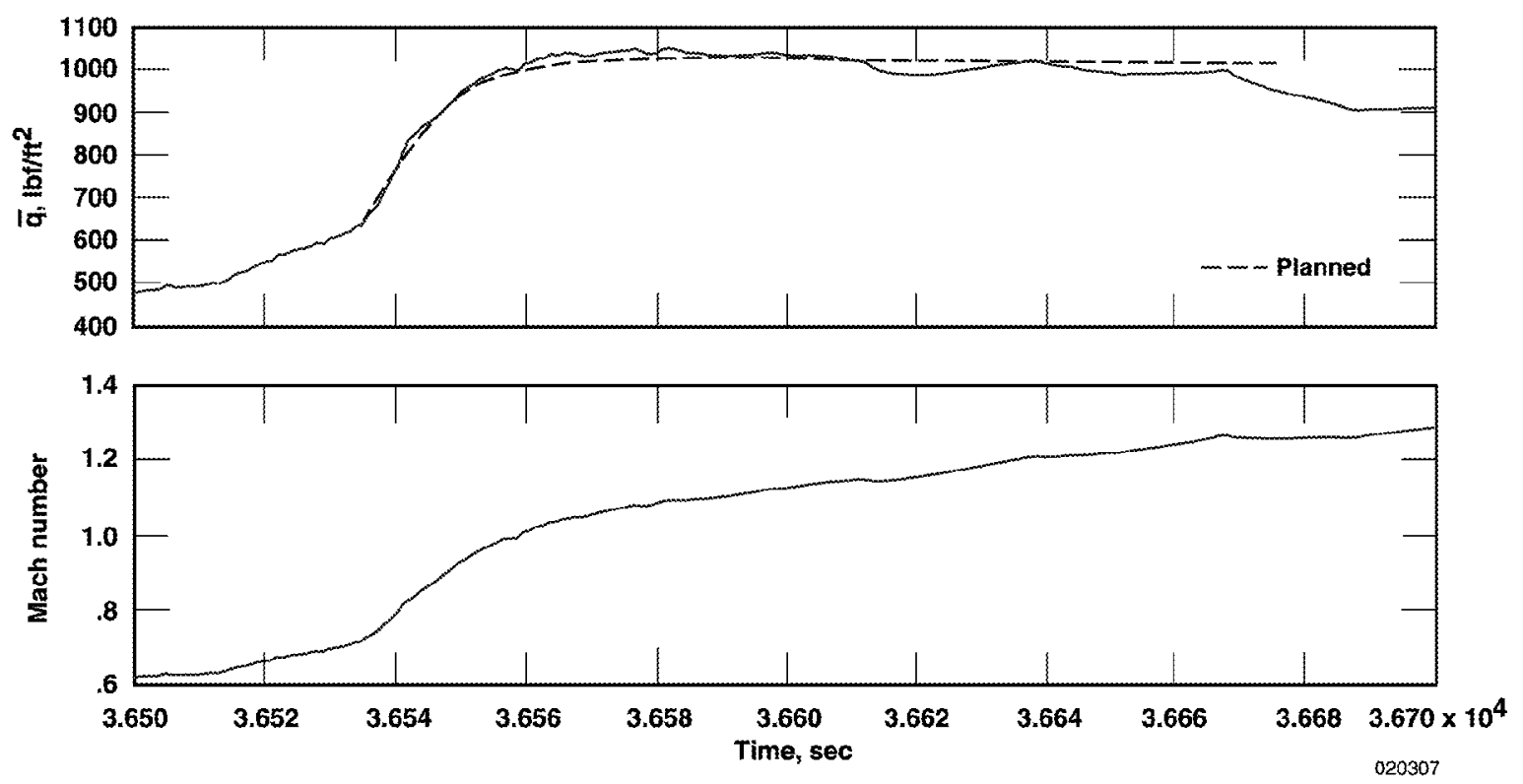

Figure 9. Flight 5 maximum-acceleration maneuver. 
section presents only force results obtained from the force balance in the axial direction. The axial aerodynamic forces were caused by air pressures on the force-balance doubler plate, the adapter, the attachment collars and bars, and the coned tube. Two conical nose sections (20- and 30-deg half-angle) were flight-tested to qualitatively assess the differential accuracy of the force balance. Quantitative assessments of the repeatability are presented, but are somewhat limited because of constraints of the flight test program.

Axial force measurements from the force balance were calculated by subtracting inertial loads in the axial direction from the measured force in the axial direction, $F_{x}$, as shown in the following equation:

$$
\text { Axial force }=F_{x}-a_{x} \times W
$$

where $a_{x}$ is the acceleration in the axial direction of the force balance and $W$ is the weight of the CDE and adapter hardware on the live side of the balance (340 lb). The coefficient of axial force, $C_{A}$, is defined using the cross-sectional area of the coned tube as the reference area and the free-stream dynamic pressure.

Repeatability of the force-balance axial force measurements can be seen in figure 10, which shows data from three low-altitude acceleration maneuvers at subsonic conditions from two flights. In all cases, the 20-deg half-angle cone tip was installed and the airplane was at approximately $2100-\mathrm{ft}$ pressure altitude and at similar mass properties and throttle settings. The maximum axial force measured in these maneuvers was approximately $375 \mathrm{lbf}$, and the repeatability was excellent. The top plot shows scatter within $\pm 15 \mathrm{lbf}$, which equates to \pm 0.75 -percent of the full-scale drag measurement capability of $\pm 2000 \mathrm{lbf}$. The $C_{A}$ plot shows the scatter in the data is roughly \pm 6 percent.

The repeatability of the force-balance axial force measurements at transonic and supersonic speeds is shown during an acceleration-deceleration maneuver (fig. 11). The repeatability of the axial force measurements between Mach 1.30 and 1.51 was excellent; however, a difference existed in $C_{A}$ values for speeds less than Mach 1.3. The $C_{A}$ values measured during the deceleration were as much as 6-percent less than the values measured during the acceleration. The exact cause of this disagreement is unknown. Possible causes include differences in throttle setting, angle of attack, and variations in altitude. The throttle setting was not instrumented; however, the acceleration was performed at a much greater throttle setting than the deceleration. The variation in shock structure off the airplane inlets caused by different thrust conditions could have affected the measured CDE axial force.
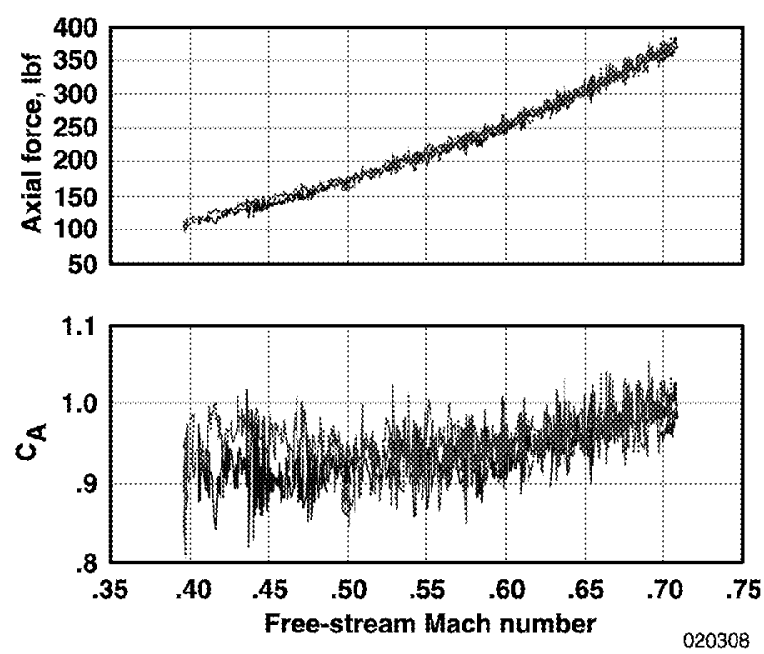

Figure 10. Repeatability of CDE axial force measurements from three nearly identical maneuvers on two flight days.

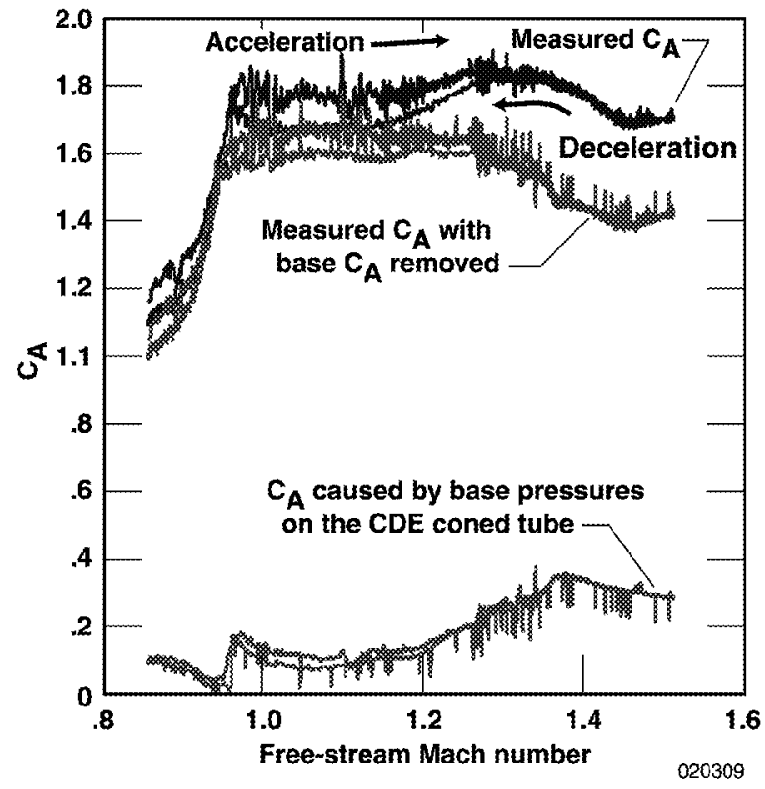

Figure 11. $\mathrm{CDE} C_{A}$ during an acceleration-deceleration maneuver (at an altitude of approximately $30 \mathrm{kft}$ ). 
Variations in angle of attack are another possible cause. The angle of attack measured as a function of Mach number generally agrees to within $0.5^{\circ}$ for the acceleration and the deceleration. Minimal differences in angle of attack, however, could appreciably affect the aerodynamic flow structure in the vicinity of the PFTF, causing noticeable differences in the axial force measurements. Altitude also could have been a factor, because the majority of the acceleration was done at an altitude of $32,000 \mathrm{ft}$ and the majority of the deceleration was done at an altitude of 29,500 ft. Altitude effects, however, would be expected to be minimal.

One additional area investigated was the axial force component generated by the base of the coned tube. The base plate is instrumented with four pressure ports (fig. 3). The base pressure measurements were averaged to obtain an approximate coefficient of base pressure. Figure 11 shows the $C_{A}$ caused by base pressure. The base $C_{A}$ also shows different results for the acceleration and deceleration. Removal of the base $C_{A}$ measurement from the total $C_{A}$ measurement results in a reduction of the difference in $C_{A}$ data for the acceleration and deceleration parts of the maneuver (fig. 11).

Data obtained during an acceleration-deceleration maneuver to a speed of Mach 2.0 at an altitude of $40 \mathrm{kft}$ show similar disagreement for the acceleration and deceleration portions of the maneuver, and similar improvement when the base $C_{A}$ component is removed (fig. 12). A nonintuitive result shown in figure 12 is that the $C_{A}$ with the base $C_{A}$ removed increases as Mach number increases beyond Mach 1.5. Wave drag is the significant axial force component at these greater Mach numbers and would be expected to decrease with increasing Mach number; however, an aerodynamic interaction between the PFTF and CDE and the F-15B airplane causes the $C_{A}$ to increase. The reason for this increase is unknown; however, the result is very repeatable through the acceleration and deceleration.

On the final flight of the program, the 20-deg half-angle nosecone was replaced with a 30 -deg one. An acceleration-deceleration maneuver at an altitude of $30,000 \mathrm{ft}$ was performed with the 30-deg half-angle nosecone installed to compare with results from flights with the 20-deg nosecone. Empirical data from reference 5 was used to estimate how much additional wave drag should be expected with the new nosecone.

Figure 13 shows the flight results for free-stream Mach numbers between 1.3 and 1.5. The data from flights with the 20-deg nosecone were used as a base to add the estimated wave drag increment caused by the

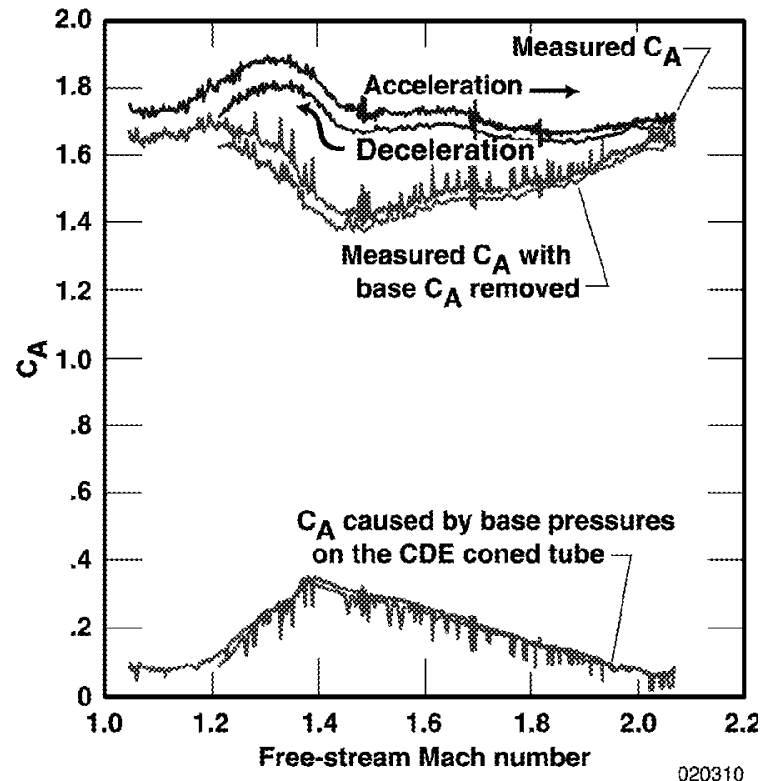

Figure 12. $\mathrm{CDE} C_{A}$ during an acceleration-deceleration maneuver (at an altitude of approximately $40 \mathrm{kft}$ ).

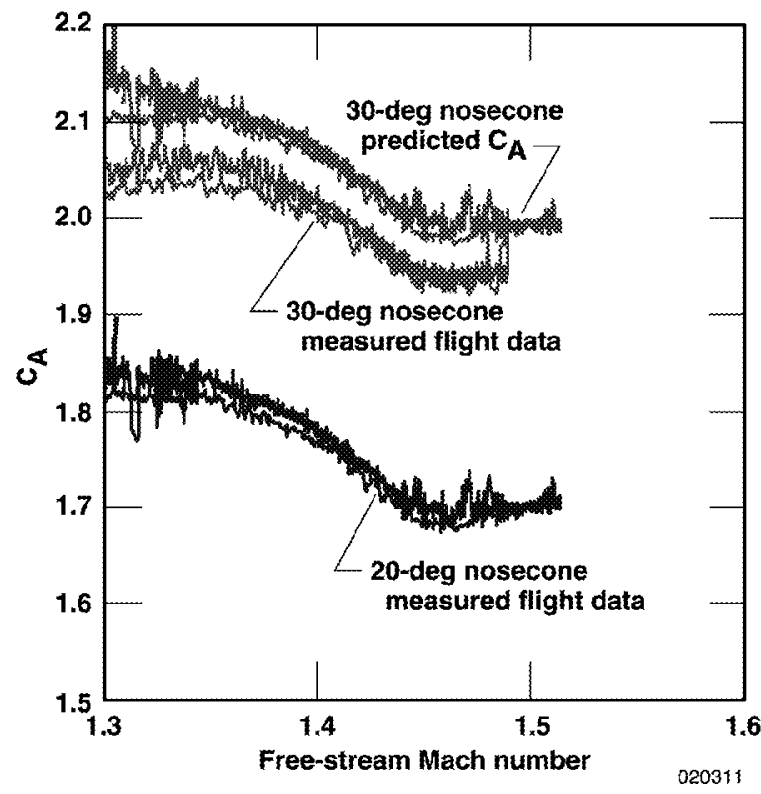

Figure 13. Comparison of estimated and flight-measured $C_{A}$ using the 30-deg nosecone.

30-deg cone. As figure 13 shows, the flight data with the 30-deg nosecone for the maneuver was approximately 3-percent less than the estimated result - or, another way of looking at this, the nosecone accounted for approximately 80 percent of the estimated wave drag 
increment. The exact reason for this difference between flight and prediction is unknown; however, some error is caused by not precisely knowing the local Mach number at the PFTF. The free-stream Mach number ranges from 1.30 to 1.50 for this maneuver; however, the local PFTF Mach number is estimated to range from 1.23 to 1.33 based on previous flight data with a local airdata measurement system.

In summary, the PFTF force balance has been shown to provide repeatable axial force measurements. The repeatability of the $C_{A}$ has been demonstrated to be well within 6 percent at all flight conditions. Use of base drag measurements has been shown to reduce some of the uncertainty. No definitive flight test has been done to quantify absolute accuracy of the force balance; however, the force balance has demonstrated good robustness and is anticipated to be well-suited for measuring incremental forces such as the increments obtained by turning a thruster on and off.

Internal Temperature

Several thermocouples were installed in the PFTF for initial flights. Three were installed to monitor temperature in the three internal bays of the PFTF and to quantify the environment that future PFTF internal components must be designed to withstand. Two additional thermocouples were located in the cavity containing the force-balance load-measuring tubes to record the temperature variations between the fore and aft parts of the force balance. Figure 14 shows results from these thermocouples for the fastest flight. This flight profile provided the most severe thermal environment. The PFTF first experienced cold high-altitude temperatures, then rapid heating as Mach number increased, providing the highest temperature difference between the fore and aft of the PFTF. The maximum temperature recorded was $135^{\circ} \mathrm{F}$ and the minimum was $3^{\circ} \mathrm{F}$. These extreme temperatures are well within typical limits for instrumentation and electronic equipment.

\section{Vibration Environment}

Figure 15 shows data from accelerometers installed on the PFTF structure. The data are confined to the low frequency because of a $400-\mathrm{Hz}$ sampling rate on the accelerometers. The figure also shows "Curve A," the random vibration curve to which equipment is ground-tested before being installed on an aircraft. ${ }^{6}$ All of the measured data lie below Curve A, with one minor exception. However, these data were taken at the maximum vibration level experienced throughout the
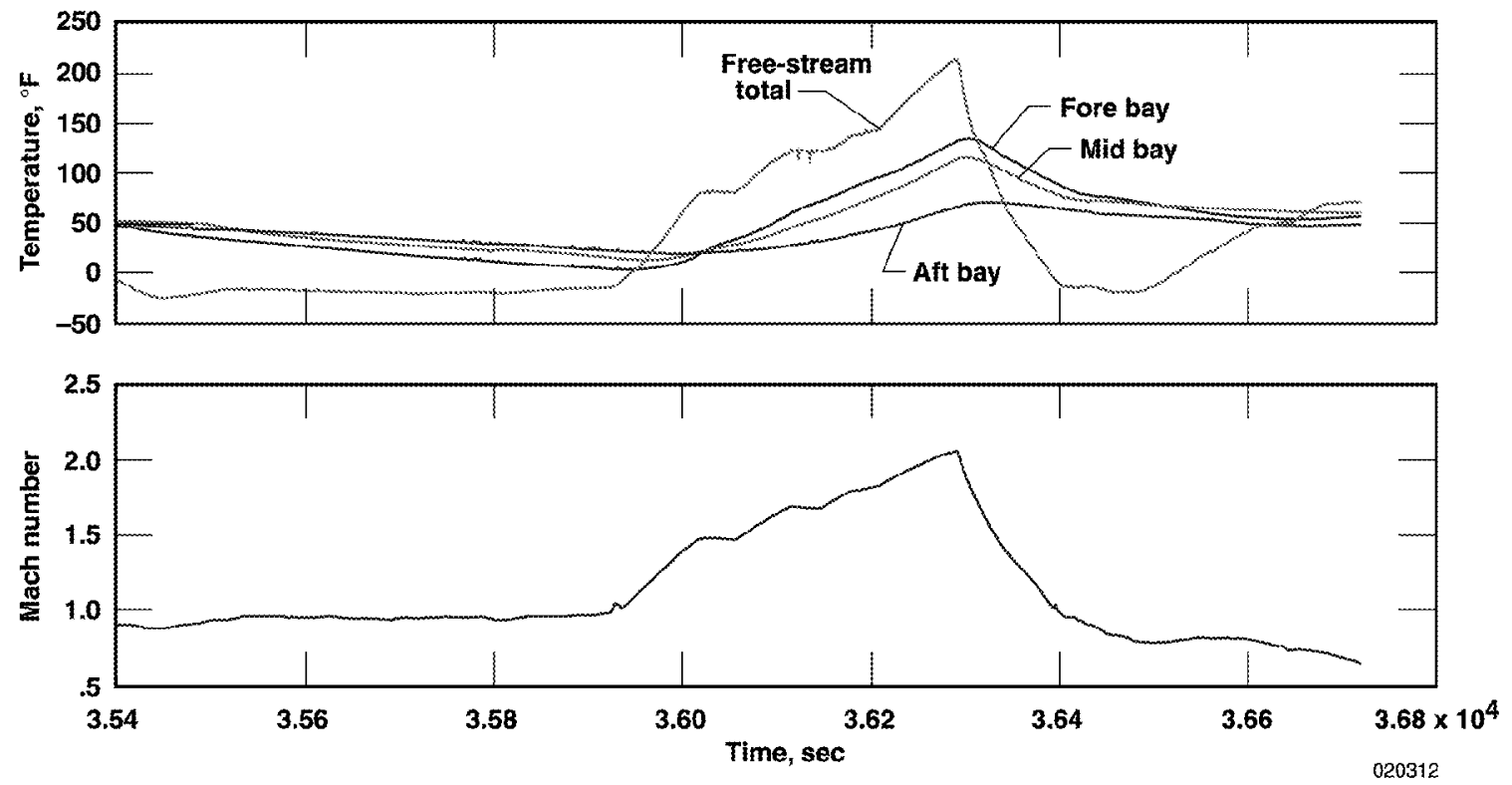

Figure 14. Bay temperatures for maximum performance flight. 
flight program. Levels greater than Curve A occurred infrequently and for very brief periods. Thus, no reason exists to believe that ground testing of equipment for the PFTF beyond Curve $A$ is necessary.

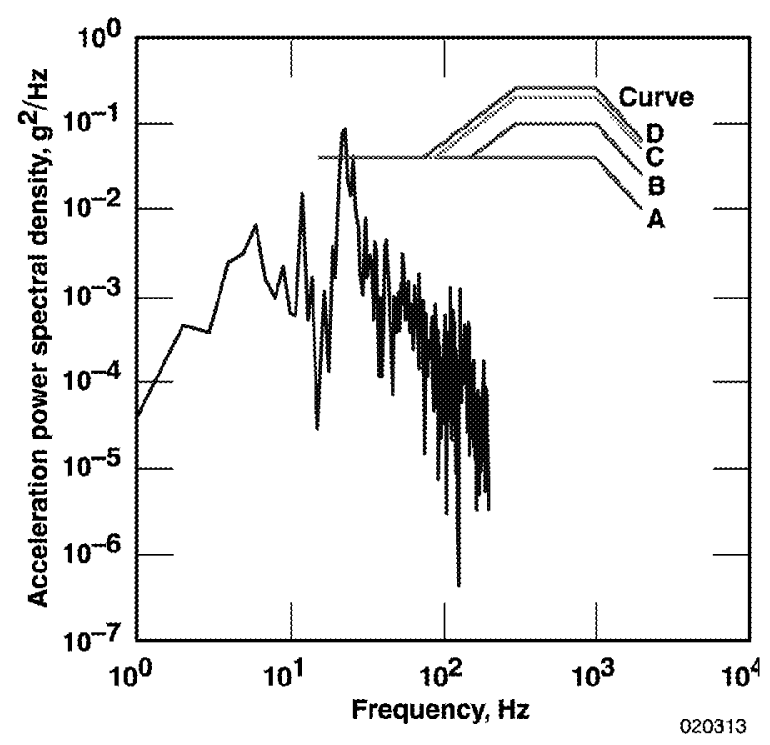

Figure 15. PFTF internal lateral vibration at the ground side of the force balance.

\section{Flow Visualization}

To ensure reasonably smooth flow around the PFTF and identify any flow anomalies, wool tufts were installed on one side of the PFTF and CDE. Two video cameras, one on the fore and one on the aft left missile rail, also were used. Figure 16 shows a frame from the fore camera. The video indicates that relatively chordwise flow conditions exist over the PFTF main structure and relatively axial flow along the length of the coned tube. Deviation from these conditions include slight downward flow turning around the front of the CDE adapter and a region of upwash and separation generated behind the aft fairing in the void between the PFTF and CDE coned tube. Also, at high subsonic-condition Mach numbers, discontinuity in the tufts indicates a possible shock wave, generated by the F-15B airplane, impinging on the PFTF just aft of the leading-edge wedge.

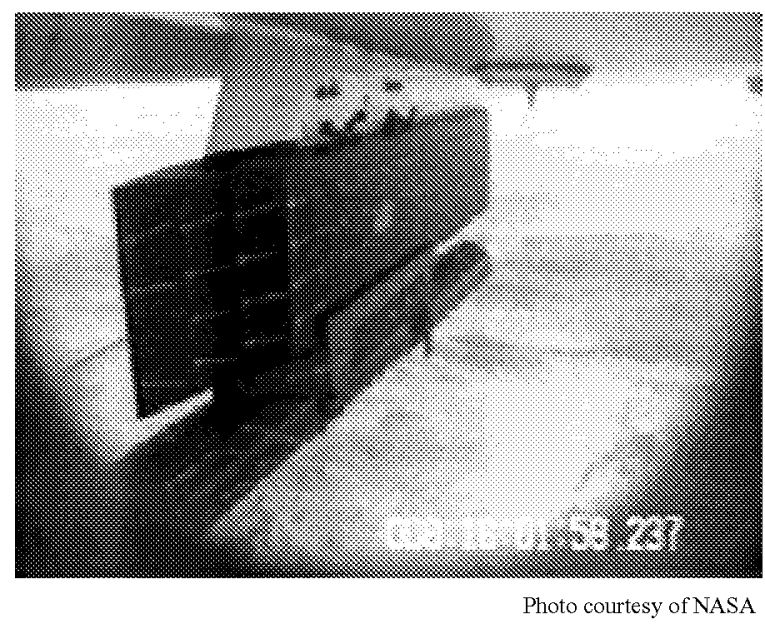

Figure 16. PFTF fore camera during flight at Mach 1.69 and an altitude of $39,700 \mathrm{ft}$.

\section{Concluding Remarks}

Initial flight tests of the NASA F-15B Propulsion Flight Test Fixture (PFTF) with a Cone Drag Experiment (CDE) were described. An overview of the PFTF and CDE was presented. Envelope clearance, maximum performance, force-balance operation, and flow visualization were the goals of the flight phase. The PFTF was flown to its design envelope while performing various maneuvers. Flight test to Mach numbers as great as 2.0 and dynamic pressure of $1120 \mathrm{lbf} / \mathrm{ft}^{2}$ was performed. All flights were performed with no significant handling qualities or flutter concerns. Axial force measurements of the CDE were presented and discussed. The force balance proved to be operationally robust for the flight environment and showed excellent repeatability in the axial direction.

The thermal environment of the PFTF internal compartments was discussed and had a maximum temperature of $135^{\circ} \mathrm{F}$ and a minimum temperature of $3{ }^{\circ} \mathrm{F}$. Results from a flight following a typical access-to-space trajectory through the transonic region were presented.

Initial flight tests have shown the F-15B/PFTF combination to be a viable option for bringing emerging propulsion technologies to flight. The "captive-carry" capability of the PFTF allows for reduced mission risk and cost than other flight test options. 


\section{$\underline{\text { References }}$}

${ }^{1}$ Burcham, Frank W., Jr. and Ronald J. Ray, The Value of Early Flight Evaluation of Propulsion Concepts Using the NASA F-15 Research Airplane, NASA TM-100408, 1987.

${ }^{2}$ Richwine, David M., F-15B/Flight Test Fixture II: A Test Bed for Flight Research, NASA TM-4782, 1996.

${ }^{3}$ Corda, Stephen, et al., The F-15B Propulsion Flight Test Fixture: A New Flight Facility for Propulsion Research, NASA TM-2001-210395, 2001.

${ }^{4}$ Tanaka, Arthur Y. and Rodrigo J. Huete, F/TF-15A Flying Qualities Air Force Development Test and Evaluation, AFFTC-TR-76-48, July 1977.

${ }^{5}$ Hoerner, Sighard F., Fluid-Dynamic Drag: Practical Information on Aerodynamic Drag and Hydrodynamic Resistance, Self-published work, Library of Congress Card Number 64-19666, Washington, D. C., 1965 , figs. 16-23.

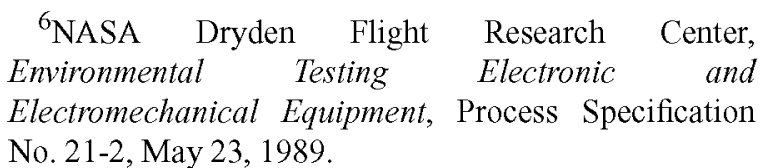


Public reporting burden for this collection of information is estimated to average 1 hour per response, including the time for reviewing instructions, searching existing data sources, gathering and maintaining the data needed, and completing and reviewing the collection of information. Send comments regarding this burden estimate or any other aspect of this collection of information, including suggestions for reducing this burden, to Washington Headquarters Services, Directorate for Information Operations and Reports, 1215 Jefferson Davis Highway, Suite 1204 , Arlington, VA 22202-4302, and to the Office of Management and Budget, Paperwork Reduction Project (0704-0188), Washington, DC 20503.

\begin{tabular}{|l|l|l|}
\hline 1. AGENCY USE ONLY (Leave blank) & $\begin{array}{l}\text { 2. REPORT DATE } \\
\text { July } 2002\end{array}$ & $\begin{array}{l}\text { 3. REPORT TYPE AND DATES COVERED } \\
\text { Technical Memorandum }\end{array}$ \\
\hline
\end{tabular}

4. TITLE AND SUBTITLE

5. FUNDING NUMBERS

Initial Flight Tests of the NASA F-15B Propulsion Flight Test Fixture

6. AUTHOR(S)

WU 710-35-14-00-38-00-F15

Nathan Palumbo, Timothy R. Moes, and M. Jake Vachon

7. PERFORMING ORGANIZATION NAME(S) AND ADDRESS(ES)

8. PERFORMING ORGANIZATION

REPORT NUMBER

NASA Dryden Flight Research Center

P.O. Box 273

Edwards, California 93523-0273

$\mathrm{H}-2507$

9. SPONSORING/MONITORING AGENCY NAME(S) AND ADDRESS(ES)

10. SPONSORING/MONITORING

AGENCY REPORT NUMBER

National Aeronautics and Space Administration

Washington, DC 20546-0001

NASA/TM-2002-210736

11. SUPPLEMENTARY NOTES

Presented at 38th AIAA/ASME/SAE/ASEE Joint Propulsion Conference and Exhibit, Indianapolis, Indiana July 7-10, 2002, AIAA-2002-4131.

12a. DISTRIBUTIONIAVAILABILITY STATEMENT

2b. DISTRIBUTION CODE

Unclassified-Unlimited

Subject Category -07

This report is available at http://www.dfrc.nasa.gov/DTRS/

13. ABSTRACT (Maximum 200 words)

Flights of the F-15B/Propulsion Flight Test Fixture (PFTF) with a Cone Drag Experiment (CDE) attached have been accomplished at NASA Dryden Flight Research Center. Mounted underneath the fuselage of an F-15B airplane, the PFTF provides volume for experiment systems and attachment points for propulsion experiments. A unique feature of the PFTF is the incorporation of a six-degree-of-freedom force balance. The force balance mounts between the PFTF and experiment and measures three forces and moments. The CDE has been attached to the force balance for envelope expansion flights. This experiment spatially and inertially simulates a large propulsion test article. This report briefly describes the F-15B airplane, the PFTF, and the force balance. A detailed description of the CDE is provided. Force-balance ground testing and stiffness modifications are described. Flight profiles and selected flight data from the envelope expansion flights are provided and discussed, including force-balance data, the internal PFTF thermal and vibration environment, a handling qualities assessment, and performance capabilities of the F-15B airplane with the PFTF installed.

\begin{tabular}{|c|c|c|c|}
\hline \multirow{2}{*}{\multicolumn{3}{|c|}{$\begin{array}{l}\text { 14. SUBJECT TERMS } \\
\text { F-15B flight testing, In-flight force balance, Propulsion flight test fixture, } \\
\text { Propulsion flight testing, Rocket-based combined cycle propulsion }\end{array}$}} & \multirow{2}{*}{$\begin{array}{l}\text { 15. NUMBER OF PAGES } \\
15 \\
\text { 16. PRICE CODE }\end{array}$} \\
\hline & & & \\
\hline $\begin{array}{l}\text { 17. SECURITY CLASSIFICATION } \\
\text { OF REPORT }\end{array}$ & $\begin{array}{l}\text { 18. SECURITY CLASSIFICATION } \\
\text { OF THIS PAGE }\end{array}$ & $\begin{array}{l}\text { 19. SECURITY CLASSIFICATION } \\
\text { OF ABSTRACT }\end{array}$ & 20. LIMITATION OF ABSTRACT \\
\hline Unclassified & Unclassified & Unclassified & Unlimited \\
\hline
\end{tabular}

